\title{
Verification of quality parameters for portal images in radiotherapy
}

\author{
Csilla Pesznyák ${ }^{1,2}$, István Polgár ${ }^{1}$, Csaba Weisz $^{1}$, Réka Király¹, Pál Zaránd ${ }^{1}$ \\ 1 Uzsoki Hospital, Municipal Centre for Oncoradiology, Budapest, Hungary \\ ${ }^{2}$ Budapest University of Technology and Economics, Institute of Nuclear Techniques, Budapest, Hungary
}

Received 5 May 2010

Accepted 10 November 2010

Correspondence to: Csilla Presznyák, PhD, Uzsoki Hospital, Municipal Centre for Oncoradiology, Uszoki street 29, H-1145 Budapest, Hungary. E-mail: csilla.pesznyak@freemail.hu

Disclosure: No potential conflicts of interest were disclosed.

Background. The purpose of the study was to verify different values of quality parameters of portal images in radiotherapy.

Materials and methods. We investigated image qualities of different field verification systems. Four EPIDs (Siemens OptiVue500aSi ${ }^{\circledR}$, Siemens BeamView Plus ${ }^{\circledR}$, Elekta iView ${ }^{\circledR}$ and Varian PortalVision ${ }^{\mathrm{TM}}$ ) were investigated with the PTW EPID QC PHANTOM ${ }^{\circledR}$ and compared with two portal film systems (Kodak X-OMAT ${ }^{\circledR}$ cassette with Kodak X-OMAT V ${ }^{\circledR}$ film and Kodak EC-L Lightweight ${ }^{\circledR}$ Cassette with Kodak Portal Localisation ReadyPack ${ }^{\circledR}$ film).

Results. A comparison of the $\mathrm{f} 50$ and $\mathrm{f} 25$ values of the modulation transfer functions (MTFs) belonging to each of the systems revealed that the amorphous silicon EPIDs provided a slightly better high contrast resolution than the Kodak Portal Localisation ReadyPack ${ }^{\circledR}$ film with the EC-L Lightweight ${ }^{\circledR}$ cassette. The Kodak X-OMAT V ${ }^{\circledR}$ film gave a poor low contrast resolution: from the existing 27 holes only 9 were detectable.

Conclusions. On the base of physical characteristics, measured in this work, the authors suggest the use of amorphous-silicon EPIDs producing the best image quality. Parameters of the EPIDs with scanning liquid ionisation chamber (SLIC) were very stable. The disadvantage of older versions of EPIDs like SLIC and VEPID is a poor DICOM implementation, and the modulation transfer function (MTF) values (f50 and f25) are less than that of aSi detectors.

Key words: electronic portal imaging device; quality control; portal film

\section{Introduction}

Electronic Portal Imaging Devices (EPIDs) are used for patient setup during radiotherapy sessions. ${ }^{1-6}$ At the same time amorphous silicon ( $\mathrm{aSi}$ ) detectors also offer the possibility of implementing transit dosimetry - this, however, requires a very good quality control protocol. ${ }^{7-10}$ A good quality control process comprises a series of procedures to be carried out regularly, with the aim of which the user may ascertain that the equipment provides good image quality and correct measured data. Users usually realize only a sudden drastic worsening of the image quality and fail to notice gradual worsening.

We tested the image qualities of different field verification systems. Four different EPIDs (Siemens OptiVue500aSi ${ }^{\circledR}$, Siemens BeamView Plus ${ }^{\circledR}$, Elekta iView $^{\circledR}$ and Varian PortalVision ${ }^{\mathrm{TM}}$ ) and two Kodak films (the X-OMAT V ${ }^{\circledR}$ film in a X-OMAT ${ }^{\circledR}$ cassette and the Portal Localisation ReadyPack ${ }^{\circledR}$ film in a EC-L Lightweight ${ }^{\circledR}$ cassette) were examined with the PTW EPID QC PHANTOM ${ }^{\circledR}{ }^{11}$

\section{Materials and methods}

The PTW EPID QC PHANTOM ${ }^{\circledR}$ was placed on the homogeneous part of the tabletop taking into account the divergence of the beam so that the whole phantom was in the image. ${ }^{12}$ The acquired images were analysed with the epidSoft ${ }^{\circledR} 2.0$ computer program. ${ }^{13}$ In our study we were interested not only in the quality of the images but also in the results given by the software for different file formats of the same image, such as JPEG, DCM, BMP, TIF, etc. We investigated the effect of different doses on the quality of the images. Figure 1 shows the 
phantom elements that were used for the calculation of different parameters.

Linearity of Copper Steps Wedges: two copper steps were used for linearity determination. The copper steps are designed in such a way that a range of $0 \%$ to $50 \%$ absorption rate is covered for a typical accelerator at $6 \mathrm{MV}$ beam energy. The linearity curve was calculated from the mean of the gray values of each of the copper steps. The results were the levels $0 \%, 5 \%, 10 \%, 15 \%, 20 \%, 25 \%, 30 \%$, $35 \%, 40 \%$ and $50 \%$. For the display an additional $45 \%$ value was calculated from the $40 \%$ and $50 \%$ values by linear interpolation.

The Local dependence of Linearity was determined by means of the brass steps in the corners and at the bottom right side of the phantom (Figure 1.2). Each of these six sets of brass steps consists of four steps, which cover approximately $10 \%, 20 \%$ and $40 \%$ absorption rate at $6 \mathrm{MV}$. Linearity curve is calculated for each block from the mean of the gray values of the steps.

Signal-to-Noise Ratio (SNR) was also determined by means of the two copper steps (Figure 1.1). The SNR was calculated for each absorption level of the copper step.

Modulation Transfer Function (MTF) and High Contrast Resolution: the regions denoted by number 5 in the middle area of the phantom in Figure 1 were used for the determination of the MTF and the high contrast resolution (in horizontal and vertical direction). The mean of the gray values of the lamellae (maximal) and the mean of the gray values of the gaps (minima) were determined for each lamella block.

The Low Contrast Resolution was determined with the help of region 4 with 27 holes having different diameters and depths (Figure 1). For each hole the contrast difference of the hole and a specified area around the hole were calculated and represented in a column diagram. The diameters and depths of the holes are similar to those of the Las Vegas phantom, but Las Vegas phantom gives only visual information, while the PTW EPID QC PHANTOM $^{\circledR}$ also gives the numeric analysis (Figure 2).

In the case of Varian's PortalVision ${ }^{\mathrm{TM}}$, the control software of the linac used 7 MUs for one portal image. ${ }^{14,15}$ The Siemens video based BeamView Plus $^{\circledR}$ was irradiated with 8,10 and 16 MUs. The EPID was irradiated with 1, 2, 4, 6 and 8 MUs in the case of the Siemens OptiVue500aSi ${ }^{\oplus}$ and the Elekta iView ${ }^{\circledR} .^{16-18}$ For portal films, we put both the phantom and the portal film cassette on the top of the treatment table. The Kodak Portal Localisation

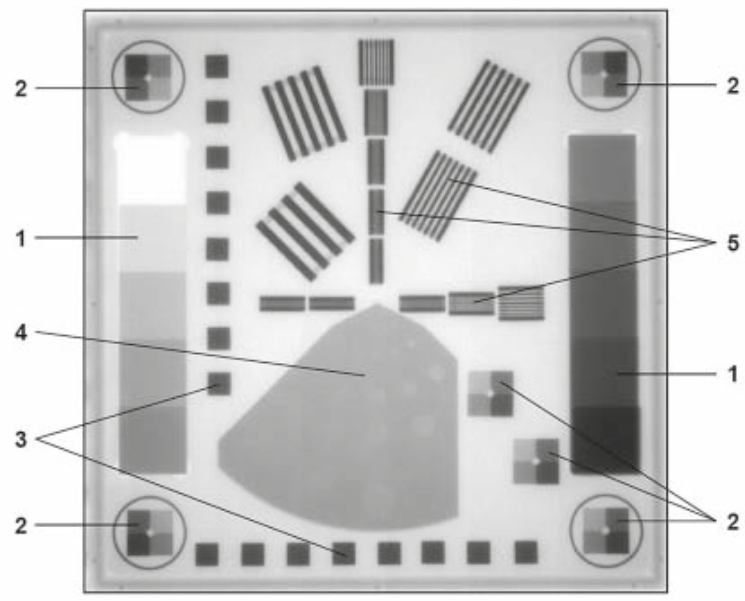

FIGURE 1. Structure of the PTW EPID QC PHANTOM ${ }^{\circledR}, 1$. Signal linearity and signal noise ratio, 2. Isotropy of signal linearity, 3. Geometric isotropy (distortion), 4. Low-contrast resolution, 5. High-contrast resolution (MTF).
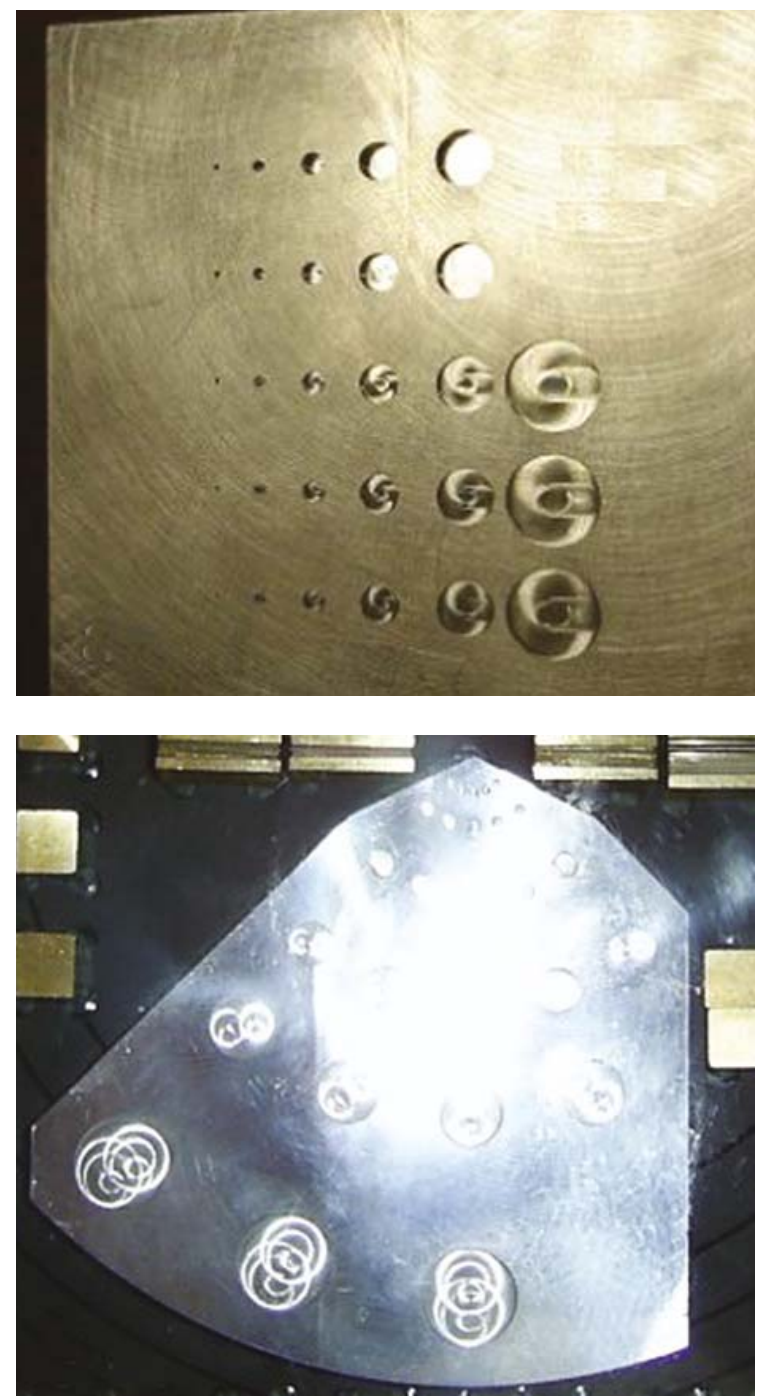

FIGURE 2. Controlling the low contrast resolution with (A) Las Vegas test tool and (B) PTW EPID QC PHANTOM ${ }^{\circledR}$. 
TABLE 1. Results of the portal image analysis with the epidSoft ${ }^{\circledR} 2.0$ program for the different equipments

\begin{tabular}{|c|c|c|c|c|c|c|c|}
\hline \multirow[t]{2}{*}{ Equipment } & \multirow[t]{2}{*}{ File format } & \multirow[t]{2}{*}{ MU } & \multicolumn{2}{|c|}{ MFT } & \multirow[t]{2}{*}{ SNR } & \multirow[t]{2}{*}{$\begin{array}{l}\text { LCSW } \\
(\%)\end{array}$} & \multirow[t]{2}{*}{$\begin{array}{l}\text { LDL } \\
\text { (\%) }\end{array}$} \\
\hline & & & $\mathrm{f} 50$ & $\mathrm{f} 25$ & & & \\
\hline PortalVision $^{\mathrm{TM}}$ & dicom 3.0 & $7+7$ & 0.288 & 0.402 & 52.8 & 0.57 & 1.43 \\
\hline PortalVision $^{\mathrm{TM}}$ & dicom Rl & $7+7$ & 0.239 & 0.342 & 2532.7 & 0.67 & 1.63 \\
\hline PortalVision ${ }^{T M}$ & $\mathrm{bmp}$ & $7+7$ & 0.251 & 0.355 & 107.3 & 0.60 & 1.50 \\
\hline BeamView Plus & bmp & 8 & 0.216 & 0.399 & 23.2 & 10.8 & 2.47 \\
\hline BeamView Plus ${ }^{\circledR}$ & bmp inverse & 8 & 0.310 & 0.435 & 37.8 & 12.8 & 2.92 \\
\hline BeamView Plus ${ }^{\circledR}$ & $\mathrm{bmp}$ & 10 & 0.242 & 0.402 & 54.2 & 11.6 & 2.75 \\
\hline BeamView Plus ${ }^{\circledR}$ & bmp & $8+8$ & 0.241 & 0.399 & 40.8 & 10.9 & 2.16 \\
\hline OptiVue500aSi ${ }^{\oplus}$ & $\mathrm{dcm}$ & 4 & 0.315 & 0.569 & 95.3 & 6.16 & 2.37 \\
\hline OptiVue500aSi ${ }^{\boxplus}$ & $\mathrm{dcm}$ & 6 & 0.315 & 0.563 & 86.4 & 6.10 & 2.32 \\
\hline OptiVue500aSi ${ }^{\circledR}$ & $\mathrm{dcm}$ & 8 & 0.315 & 0.563 & 72.9 & 6.08 & 2.23 \\
\hline Elekta iView ${ }^{\circledR}$ & $\mathrm{bmp}$ & 1 & 0.323 & 0.597 & 115.3 & 5.07 & 1.58 \\
\hline Elekta iView ${ }^{\circledR}$ & $\mathrm{bmp}$ & 2 & 0.324 & 0.602 & 102.9 & 5.01 & 1.18 \\
\hline Elekta iView ${ }^{\circledR}$ & bmp & 4 & 0.321 & 0.576 & 99.2 & 5.06 & 1.28 \\
\hline Elekta iView ${ }^{\circledast}$ & $\mathrm{bmp}$ & 6 & 0.315 & 0.572 & 90.8 & 5.03 & 1.48 \\
\hline Elekta iView ${ }^{\circledR}$ & $\mathrm{bmp}$ & 8 & 0.305 & 0.539 & 72.4 & 4.67 & 1.34 \\
\hline X-OMAT ${ }^{\oplus}$ film & $\mathrm{bmp}$ & 20 & 0.322 & 0.609 & 248.1 & 4.62 & 1.52 \\
\hline EC-L ${ }^{\circledR}$ film & dicom RI & 6 & 0.306 & 0.563 & 88.6 & 6.84 & 3.96 \\
\hline EC-L ${ }^{\circledR}$ film & tif & 1 & 0.324 & 0.572 & 113.1 & 4.97 & 1.89 \\
\hline EC-L ${ }^{\circledR}$ film & tif & 2 & 0.312 & 0.563 & 119.9 & 4.66 & 2.48 \\
\hline EC-L ${ }^{\circledR}$ film & tif & 4 & 0.324 & 0.584 & 110.2 & 4.96 & 1.71 \\
\hline EC-L ${ }^{\circledR}$ film & tif & 10 & 0.291 & 0.600 & 88.2 & 10.02 & 3.63 \\
\hline
\end{tabular}

**LCSW, Linearity of Copper Step Wedge

***LDL, Local Dependence of Linearity

ReadyPack ${ }^{\circledR}$ film was irradiated with 1, 2, 4, 6 and 10 MUs, while for Kodak X-OMAT V ${ }^{\circledR}$ film we used 7, 20 and 40 MUs, because it's lower sensitivity. We digitized the films with the LUMISYS Lumiscan ${ }^{\circledR}$ 50 with two different softwares. One was the PTW's Mephysto ${ }^{\circledR}$ program, where we saved the images in TIF and PTW file format, and the oth- er was the P2 System LumiDicom ${ }^{\circledR}$ program $^{19,20}$, where we saved the images in DCM and BMP file format. The reference values shall be determined during the acceptance test of the equipment. In the measurement protocol, the usable file format shall be defined since the implementation of DICOM is not complete at these systems. 


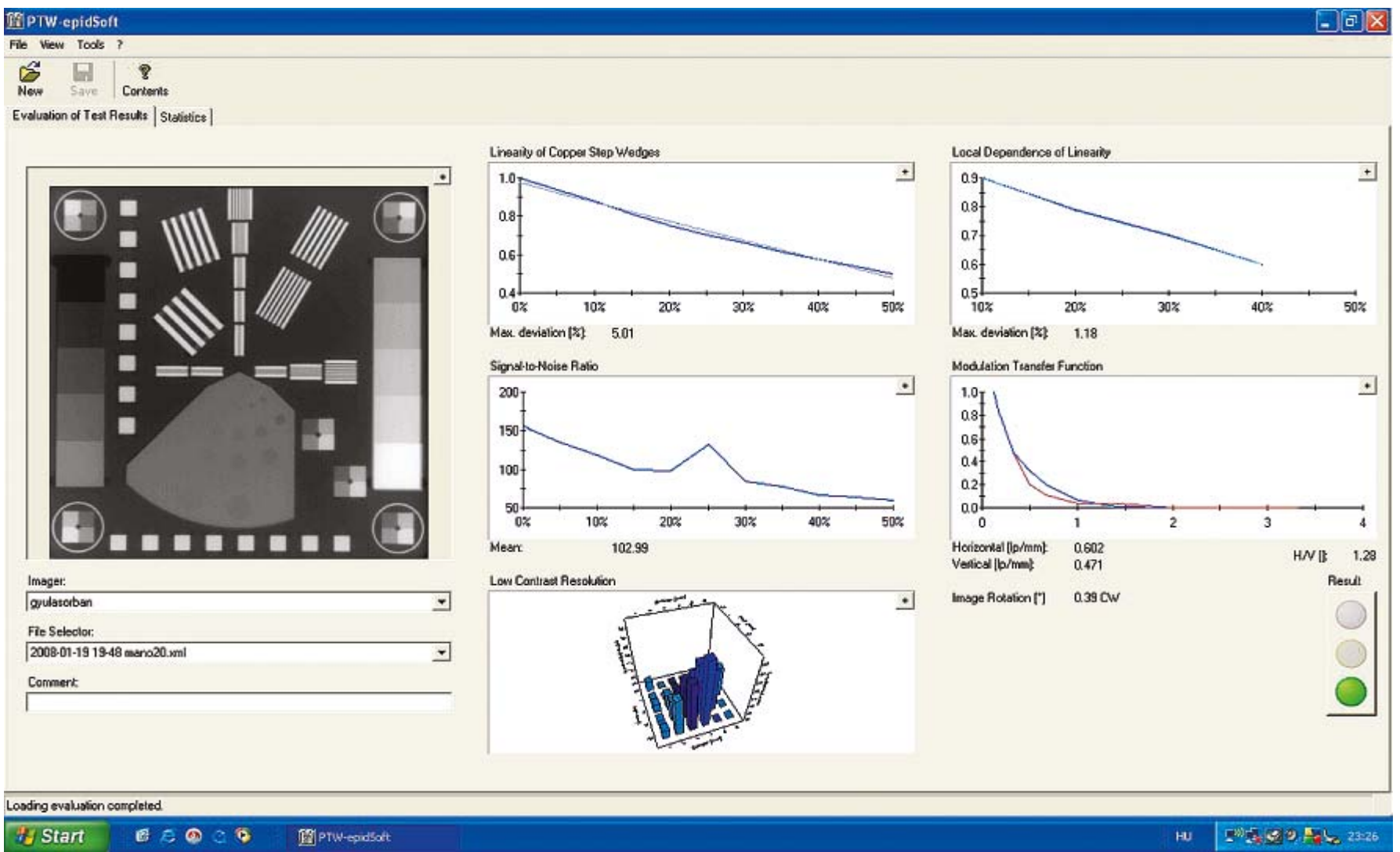

FIGURE 3. The image analysis with the epidSoft ${ }^{\circledR} 2.0$ program.

\section{Results and discussion}

The epidSoft ${ }^{\boxplus} 2.0$ program makes both, the numeric and the graphic analysis of the portal images; a screenshot can be seen in Figure 3. We analysed about 70 images taken under different conditions (Table 1). Comparing the $\mathrm{f} 50$ and $\mathrm{f} 25$ values of the MTF we resolved that the amorphous silicon EPID provides the best high contrast resolution. These results were very close to the MTF of the Kodak Portal Localisation ReadyPack ${ }^{\circledR}$ film with the EC-L Lightweight $^{\circledR}$ cassette. For the MTF f50 and f30 we found few published data in the international literature ${ }^{21-23}$; these are listed in Table 2. We also tested the constancy of the characteristics in the case of Varian's PortalVision ${ }^{\mathrm{TM}}$ images with PTW EPID QC Phantom ${ }^{\circledR}$. The graphic interpretation of the measurements is in Figure 5. In Figure 3, the upper left diagram, the measured values of daily Linearity of Copper Step Wedge curves are compared with those of calculated from the linear regression line of daily measurements on the base of equation 1.

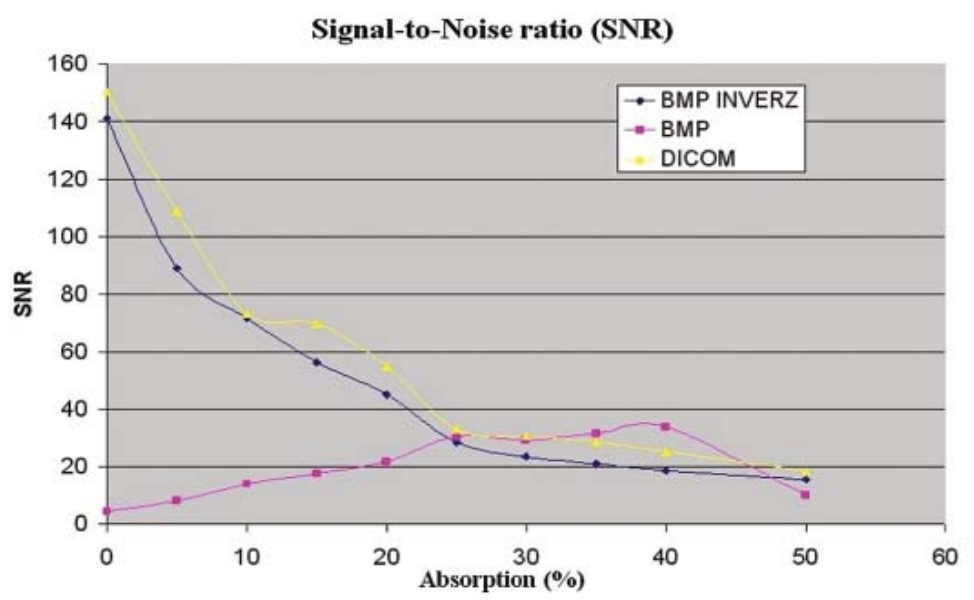

FIGURE 4. SNR as a function of absorption for Siemens BeamView Plus ${ }^{\circledR}$ in the case of different file format: DICOM, bmp and inverse bmp.

$d_{\max }=\max \left[\frac{\left|y_{i}-I_{i}\right|}{I_{i}}\right]$

$i=0 \ldots . N$

The linearity curve is given by the points $\left(\mathrm{x}_{1}, \mathrm{y}_{1}\right)$, $\ldots\left(\mathrm{x}_{\mathrm{N}}, \mathrm{y}_{\mathrm{N}}\right)$ and the regression line is given by the points $\left(\mathrm{x}_{1}, \mathrm{I}_{1}\right), \ldots\left(\mathrm{x}_{\mathrm{N}}, \mathrm{I}_{\mathrm{N}}\right)$. 
TABLE 2. Demonstration of the quantities to be used for the quality control of the EPIDs found in the references

\begin{tabular}{|c|c|c|c|c|c|c|}
\hline EPID & Pixel matrix & $\begin{array}{l}\text { Pixel size } \\
(\mathrm{mm})\end{array}$ & Dose (MU) & CNR & $\mathrm{f} 50(\mathrm{Ip} / \mathrm{mm})$ & $\mathrm{f} 30(\mathrm{Ip} / \mathrm{mm})$ \\
\hline \multicolumn{7}{|c|}{ Clements at al. 2002, PIPSpro® QC-3V fantom [1 18] } \\
\hline Varian aS $500^{\mathrm{TM}}$ & $512 \times 384$ & 0.78 & 5 & 260 & 0.392 & 0.600 \\
\hline Elekta iViewGT® & $1024 \times 1024$ & 0.4 & 100 & 448 & 0.461 & 0.767 \\
\hline Siemens FP-A & $1024 \times 1024$ & 0.4 & 100 & 611 & 0.454 & 0.696 \\
\hline \multicolumn{7}{|c|}{ Hermann at al. 2001. [119] } \\
\hline BeamView Plus® & $512 \times 512$ & & & & 0.204 & \\
\hline PortalVision ${ }^{\mathrm{TM}}$ & $256 \times 256$ & & & & 0.258 & \\
\hline \multicolumn{7}{|c|}{ Wong, 1999. [120] } \\
\hline BeamView Plus® & $512 \times 512$ & & & & $\begin{array}{l}0,214 \\
0,192(15 \mathrm{MV})\end{array}$ & \\
\hline PortalVision ${ }^{\mathrm{TM}}$ & $256 \times 256$ & & & & 0,258 & \\
\hline
\end{tabular}
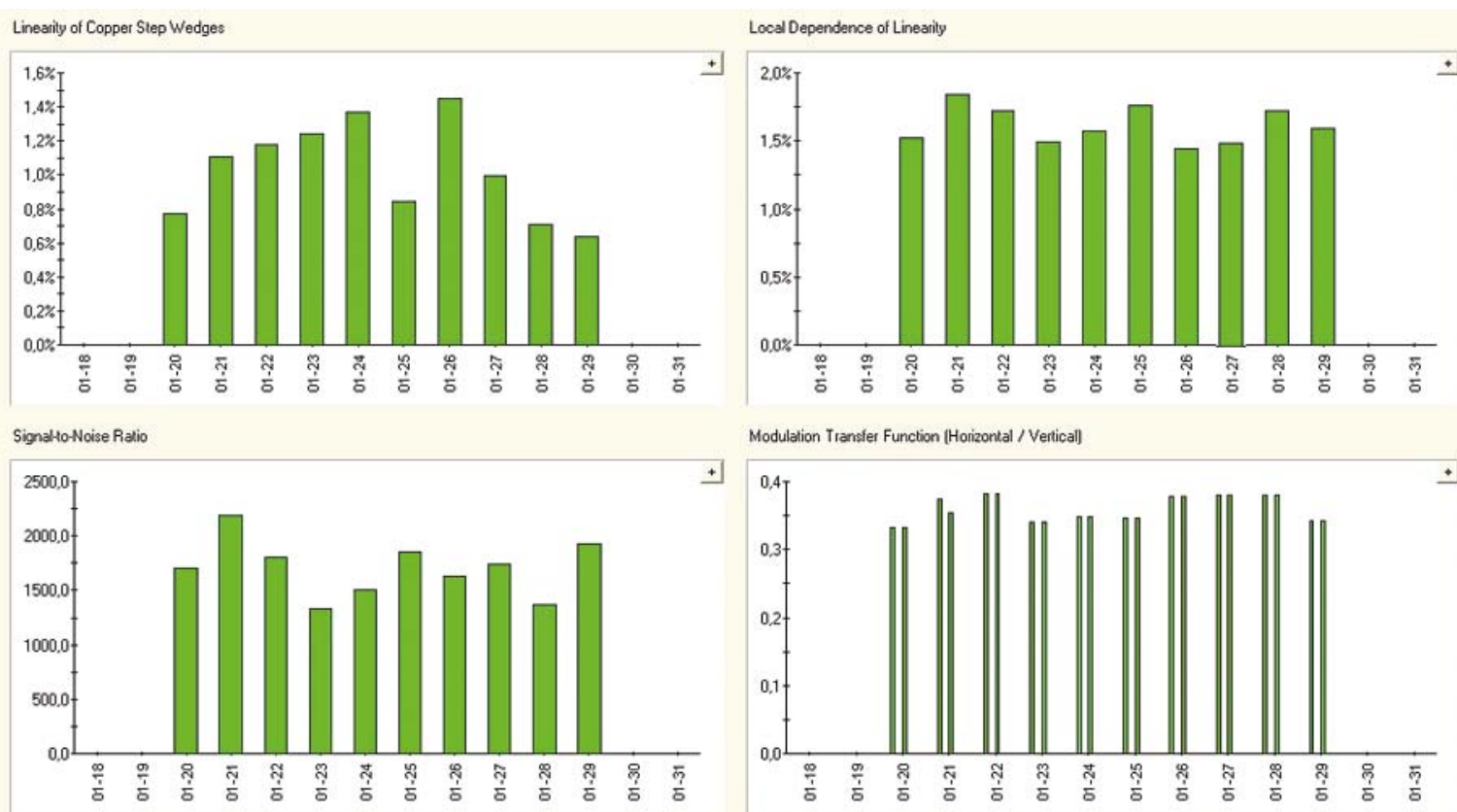

Modulation Transer Function (Horizontal / Vertical)

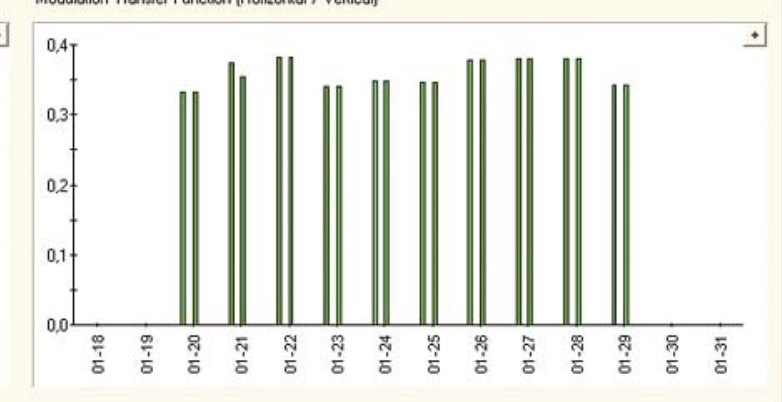

FIGURE 5. The graphic representation of the Varian PortalVision ${ }^{\text {TM }}$ equipment's stability test: A. linearity of copper step wedge, B. local dependence of linearity, C. MTF f(25) vertical and horizontal component, D. signal-to-noise ratio average value.

We have determined the 10 days stability of the system. The daily maxima are plotted vs. time in a 10 days interval in the upper left diagram of Figure 5 . The maximum of the daily deviation is on an average $1.03 \pm 0.27 \%$ representing a sufficient stability of the measurement system. A similar analysis was made for the Local Dependence of Linearity resulting in $1.62 \pm 0.19 \%$ average daily maximum deviation. For the signal-to-noise curve, the average of mean value and standard deviation, were $1656 \pm 189$. The average value for MTF f50 was $0.247 \pm 0.011 \mathrm{lp} / \mathrm{mm}$ and for MTF $\mathrm{f} 25$ we received $0.360 \pm 0.018 \mathrm{lp} / \mathrm{mm}$. Measurements shown in the Figure 5 represent a good stability of the system.
The signal-to-noise curve for the Siemens BeamView Plus ${ }^{\circledR}$ and the Varian's PortalVision ${ }^{\mathrm{TM}}$ depend of the image file format. In Figure 5 we can see the Siemens BeamView Plus ${ }^{\circledR}$ SNR curves for DICOM, BMP and the inverse BMP file format. We supposed that two older generations of EPIDs had a DICOM implementation problem. ${ }^{24}$

If we use the Las Vegas phantom for quality control, then the image quality is acceptable when we can see 17 holes from 28 holes. ${ }^{25}$ We applied the same criteria for the PTW EPID QC PHANTOM ${ }^{\circledR}$. All equipments gave good results, except the Kodak X-OMAT $\mathrm{V}^{\circledR}$ film: we found only 9 holes after irradiating the film with a 10 times higher dose 


\begin{tabular}{|c|c|c|c|c|c|c|c|}
\hline \multicolumn{8}{|c|}{ Depth [mm] } \\
\hline & & $\mathbf{0 , 5}$ & $\mathbf{1 , 0}$ & $\mathbf{2 , 0}$ & $\mathbf{3 , 2}$ & $\mathbf{4 , 8}$ \\
\hline & $\mathbf{1}$ & 0.23 & 0.16 & 0.17 & 0.86 & 0.16 \\
\hline & $\mathbf{2}$ & 0.00 & 0.01 & 0.00 & 0.06 & 0.46 \\
$\mathrm{D}$ & $\mathbf{4}$ & 0.00 & 0.14 & 0.17 & 0.14 & 0.68 \\
{$[\mathrm{~mm}]$} & $\mathbf{7}$ & 0.07 & 0.14 & 0.21 & 0.78 & 1.17 \\
& $\mathbf{1 0}$ & 0.071 & 0.76 & 0.66 & 1.21 & \\
& $\mathbf{1 5}$ & 0.04 & 0.49 & 0.74 & & \\
\hline
\end{tabular}

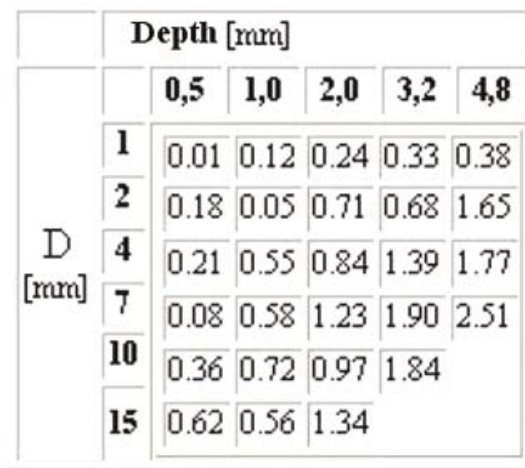
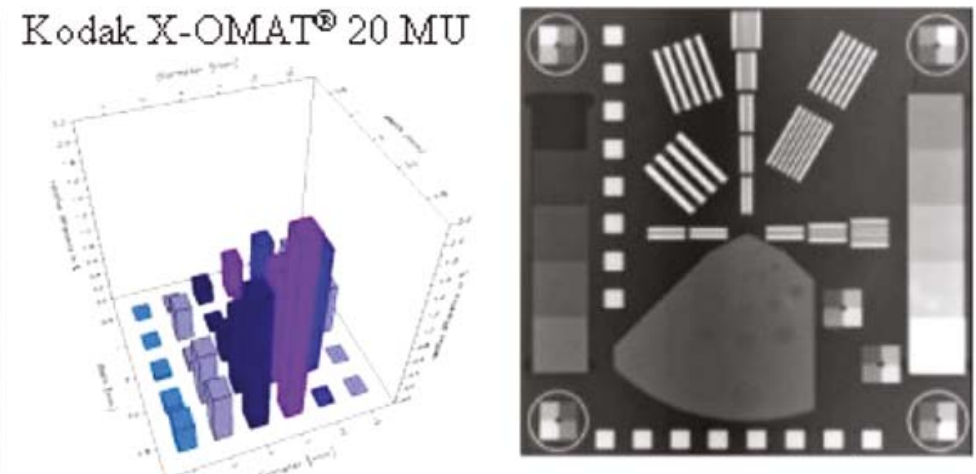

\section{Kodak EC-L 2 MU}

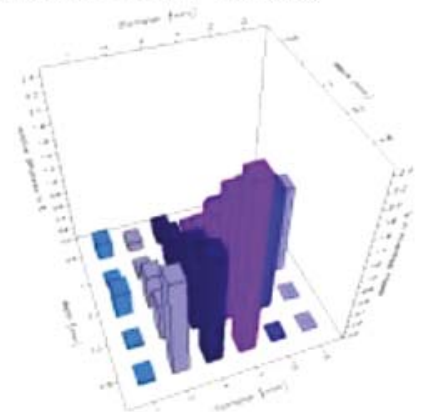

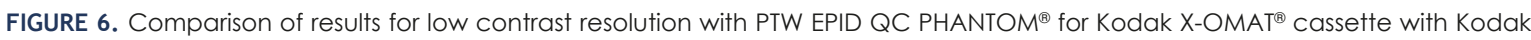
X-OMAT V ${ }^{\circledR}$ film and the Kodak EC-L Lightweight ${ }^{\circledR}$ cassette with Kodak Portal Localisation ReadyPack ${ }^{\circledR}$ film.

than the Kodak Portal Localisation ReadyPack ${ }^{\circledR}$ film. The numeric and graphic interpretation of the low contrast resolution for portal films is in the Figure 6.

When the Kodak Portal Localisation ReadyPack ${ }^{\circledR}$ film with EC-L Lightweight ${ }^{\circledR}$ cassette was overexposed (Table 1), we received a too large value for Linearity of Copper Step Wedge and the image was unusable for the verification of patient setup.

Unfortunately, there is not a lot of published information regarding the physical characteristics of different EPIDs making it difficult to compare these results. On the base of physical characteristics, measured in this work, the authors suggest the use of aSi EPIDs producing the best image quality. Parameters of the EPIDs with scanning liquid ionisation chamber (SLIC) were very stable. The disadvantage of older versions of EPIDs like SLIC and VEPID is a pour DICOM implementation, and the modulation transfer function (MTF) values ( $f 50$ and f25) are less than that of aSi detectors.

\section{Acknowledgments}

The authors thank PTW Freiburg GmbH and its Hungarian representative CANBERRA-PACKARD
Ltd. for lending the EPID QC PHANTOM ${ }^{\circledR}$ and epidSoft ${ }^{\circledR} 2.0$ program free of charge.

\section{References}

1. Boyer AL, Antomuk L, Fenster A, Van Herk M, Meertens $H$, Munro $P$, et al. A review of electronic portal imaging devices (EPIDs). Med Phys 1992; 19: 1-16.

2. Langmack K A, Phil D. Portal imaging. Brit J Radiol 2001; 74: 789-804.

3. Whittington $R$, Bloch $P$, Hutchinson $D$, Björrngard BE. Verification of prostate treatment setup using computed radiography for portal imaging. J App/ Clin Med Physi 2002; 3: 88-96.

4. Johnson LS, Milliken BD, Hodley SW, Pelizzari CA, Haraf DJ, Chen GTY. Initial clinical experience with a video-based patient positioning system. Int $J$ Radiat Oncol Biol Phys 1999; 45: 205-13

5. Pesznyák Cs, Lövey K, Weisz Cs, Polgár I, Mayer Á. Elektronikus mezőellenőrzés lineáris gyorsítón. Magyar Onkológia 2001; 45: 335-41.

6. Kasabašić M, Faj D, Belaj N, Faj Z, Tomaš I. Implementing of the offline setup correction protocol in pelvic radiotherapy: safety margins and number of images. Radiol Oncol 2007; 41: 48-55.

7. Cremers F, Frenzel Th, Kausch C, Albers D, Schonborn T, Schmidt R. Performance of electronic portal imaging devices EPIDs used in radiotherapy: Image quality and dose measurements. Med Phys 2004; 31: 985-96.

8. Petrovic B, Grzadziel A, Rutonjski K, Slosarek K: Linear array measurements of enhanced dynamic wedge and treatment planning system (TPS) calculation for $15 \mathrm{MV}$ photon beam and comparison with electronic portal imaging device (EPID) measurements. Radiol Oncol 2010; 44: 199-206.

9. Nijsten SMJJG, Mijnheer BJ, Dekker LAJ, Lambin P, Minken AWH. Routine individualised patient dosimetry using electronic portal imaging devices. Radiother Oncol 2007; 83: 65-75. 
10. Bailey DW, Kumaraswamy L, Podgorsak MB. A fully electronic intensitymodulated radiation therapy quality assurance (IMRT QA) process implemented in a network comprised of independent treatment planning, record and verify, and delivery systems. Radiol Oncol 2010; 44: 124-30.

11. Geyer P, Blank H, Alheit H. Portal verification using the KODAK ACR 2000 RT storage phosphor plate system and EC films. Strahlenther Onkol 2006; 182: $172-8$.

12. Pesznyák Cs, Fekete G, Mózes Á, Kiss B, Király R, Polgár I, et al. Quality control of portal imaging with PTW EPID QC phantom". Strahlenther Onkol 2009; 185: 56-60.

13. Epid QC phantom and epidSoft software. Users manual. Freiburg: PTW 2006.

14. Van Herk M, Meertens H. A matrix ionisation chamber imaging device for on-line patient set up verification during radiotherapy. Radiother Oncol 1988; 11: 369-78

15. Essers M, Hoogervorst BR, van Herk M, Lanson H, Mijnheer BJ. Dosimetric characteristics of a liquid-filled electronic portal imaging device. Int J Radiat Oncol Biol Phys 1995; 33: 1265-72.

16. El-Mohri Y, Jee KW, Antonuk LE, Maolinbay M, Zhao Q. Determination of the detective quantum efficiency of a prototype, megavoltage indirect detection, active matrix flat-panel imager. Med Phys 2001; 28: 2538-49.

17. Munro $P$, Bouius DC. X-ray quantum limited portal imaging using amorphous silicon flat-panel arrays. Med Phys 1998; 25: 689-702.

18. Winkler P, Hefner A, Georg D. Dose-response characteristics of amorphous silicon EPID. Med Phys 2005; 32: 3095-105.

19. Pesznyák Cs, Zaránd $P$, Mayer Á. Digitalization and networking of analog simulators and portal images. Strahlenther Onkol 2007; 183: 117-20.

20. Pesznyák Cs, Zaránd P, Baráti Zs, Párkányi T. Mevasim szimulátor hálózatbanDICOM RT. In: Pintye É, editor. Proc. X. Hungarian medical physics conference \& workshop. Debrecen: Cívis Copy Ltd.; 2004. p. 103-8.

21. Clements R, Luchka K, Pouliot J, Sage J, Shalev S. Initial comparison of three Am-Si EPIDs using the QC-3V Phantom. The 7th international workshop on electronic Portal Imaging - EPI2K2. Vancouver, BC, June, 27-29; 2002.

22. Herman MG, James MB, David AJ, McGee KP, Munro P, Shalev S, at al. Clinical use of electronic portal imaging: report of AAPM Radiation Therapy Committee Task Group 58. Med Phys 2001; 28: 712-37.

23. Wong J. Current status of electronic portal imaging. AAPM 41st annual meeting. Nashville, Tennessee; 1999.

24. NEMA (National Electrical Manufacturers Association). Digital imaging and communications in medicine (DICOM). Part 3: Information object definitions. Rosslyn: NEMA; 2003. p. 855

25. McGarry CK, Grattan MWD, Cosgrove VP. Optimisation of image quality and dose for Varian aS500 electronic portal imaging devices (EPIDs). Phys Med Biol 2007; 52: 6865-77. 